\title{
Performance Research of Four Switch Three Phase Inverter-Fed Induction Motor Drive at Low Speed Using Fuzzy Logic and Artificial Neural Network
}

\author{
Shivam Bhati, Professor S.K. Jha, Prerna Gaur
}

\begin{abstract}
This paper compares the different dynamic properties of indirect field oriented control (IFOC) of induction motor which is fed from a three phase Four switch inverter(FSTP) and comparison has been drawn between Fuzzy logic control (FLC) and Artificial Neural Network (ANN). MATLAB Simulink model is used and it has been found that the ANN method improves dynamic properties of induction motor.

Index Term--- FLC, FSTP Inverter, IFOC.
\end{abstract}

\section{INTRODUCTION}

THREE-PHASE induction motor is one of the highly used and proficient motor in the market. Inverter are considered as an important part of AC motor drive. Usually six-switch three phase inverter are used in different industrial application. Inverter has a very wide spectrum of use in industries. Six switch inverters are considered to have a disadvantage in low power application. Because of the extra switch these inverter's result in high losses and complicated controlling... Low cost application is very important and to create that driving system we replaced the traditional sex switch inverter with that of four switch inverters. Different configuration of these inverter is discussed in [1]. Currently a lot of research work has been done on FSTP inverters, not only in drives but these inverters are applicable in renewable application [2]. FSTP inverter's have fair share of advantages over SSTP inverter's in term of (i) Power loss, (ii) cost of device (iii) switching system. With FSTP we require less complicated switching algorithm and less complicated switching layers. IM control is a challenging task because of it's non linear model and parameter changes. In usual approach there are PI, PID controller which we often use. But these controllers are very much depending on the parameter variation so, this results in in accuracy. So, PI, PID controller cannot give proper result in speed tracking and load impact conditions. [3].

Now a day's various research work has been taking place in the field of artificial intelligence which include ANN and FLC. These techniques have a lot of merit over the traditional PI and PID controller. The main advantage of AI controller is that there working are not that affected by the mathematical model and performance is on the spot. [3] [49]. Controlling of IM is done with the help of IFOC. In IFOC rotor flux is essential for the rotor positioning. Field orientation concept implies that the current component supplied to the machine should be oriented in the phase and in quadrature to the rotor flux vector using sensor for direct measurement of rotor flux gives direct measurement of rotor flux gives correct values without sensitivity to machine parameters. But this method is costly and result in error in noisy environment.

So, predicting of flux depends upon the dynamic model of the IM which is essential for better performance of IFOC of IM drive. Problem with machine is that it's parameter changes as the operating condition changes. With the change in machine parameters machine working got interrupted.

In low speed region varying of machine parameters can be recognizable of lesser speed operation. At speed less than $2 / 3$ of full speed both FSTP and SSTP inverter works same [1]. So, basically FSTP inverter works properly up to $2 / 3$ of maximum speed. For speed greater that $2 / 3$ of maximum speed there will be a requirement of DC link voltage to carryout IFOC and acquire same performance for FSTP inverter. Past work has been done in the field of FLC controlled IM derives [3], [4-10].

There are some paper which analyze the FLC based IM fed from FSTP inverter all those papers are based on the high-speed application and low speed application is left out [10]. So, this paper will help us to understand the comparison of FLC based speed control and ANN based speed control method.

\section{MATHIMATICAL MODEL IM AND FSTP INVERTER}

IM motor is shown by using $\mathrm{d}-\mathrm{q}$ axis and control of IM depends upon IFOC. IFOC is elaborately explained in [11].

MATLAB Simulink of FLC based induction motor which is powered by FSTP inverter is shown in fig 1. So input to the FLC are error between reference, motor speed and derivative of error and its output is torque $\left(\mathrm{T}_{e}\right)$. Output of FLC is used to generate $\mathrm{d}-\mathrm{q}$ reference current. There reference current are converted into reference $i_{a b c}$ current by using inverse parks transformation. By using sensor we will obtain actual $i_{a b c}$ and both the above currents are given into hysteresis controller which will generate switching of inverter.

\footnotetext{
Manuscript received September 16, 2019.

Shivam Bhati, NSIT. (e-mail: bhatishivam93@gmail.com)

Professor S.K. Jha, NSIT.

Dr. Prerna Gaur, NSIT.
} 


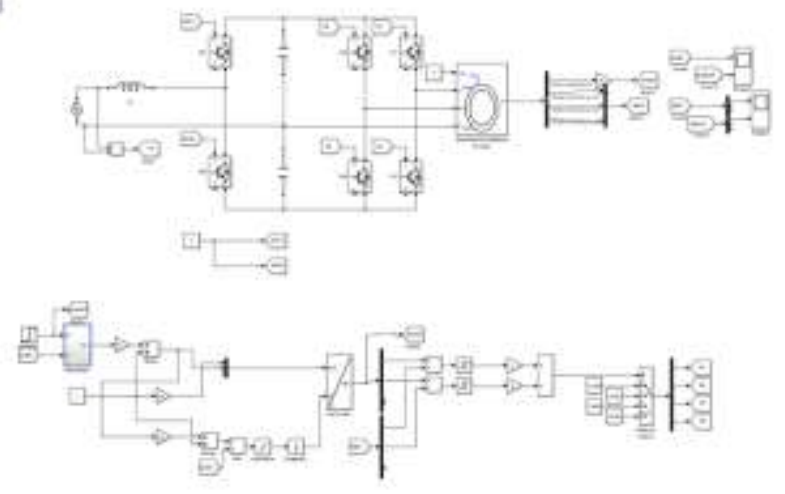

Fig. 1: Simulink Block Diagram of FLC based system

Circuit of FSTP inverter is shown in Fig 1. This circuit has two parts, first part is rectifier and other part is inverter. Switches which are used are IGBT. These IGBT have diode antiparallel to it. First pair of switches are used as rectifier which are supplied by a single phase supply, with a constant frequency. Inverter part consist of two limbs which consist of four switch. Phase $a$ and $b$ are obtain from inverter part and phase $\mathrm{c}$ is used to charge the capacitor bank which then provide the third phase for the machine. Phase voltage can be expressed in term of switch sequence of inverter and capacitor dc link voltage by the following equation [10].

$$
\begin{aligned}
V_{a} & =\frac{V_{d c}}{3}\left(4 S_{a}-2 S_{b}-1\right) \\
V_{b} & =\frac{V_{d c}}{3}\left(-2 S_{a}+4 S_{b}-1\right) \\
V_{c} & =\frac{V_{d c}}{3}\left(-2 S_{a}-2 S_{b}+2\right)
\end{aligned}
$$

Where $V_{d c}$ is the dc link voltage and $S_{a}$ and $S_{b}$ are the two binary variable which are used to control the conduction of inverter.

\section{SPEED CONTROL TECHNIQUE}

\section{FLC Technique}

FLC is used in the IM to overcome the main problem related to the parameter variation and disturbance. Input to the FLC block has been discussed already. Output of the FLC block is the torque and reference flux is used to obtain reference quadrature and direct axis reference current [12]. By using inverse peak transformation we will obtain three phase reference current. Purpose of FLC block is make sure output motor speed should be as close to the reference speed as a result motor current are kept close to the reference motor current. Calculation of reference torque depends upon the model of IM and parameter but the problem is that these parameter do not remain constant. Controller like FLC are used to deal with the variation of parameter at low speed which is very significant. Block diagram of FLC controller has been show in figure 2 it contain a memory block. Membership functions are made based on the rule which we design in FLC block. Total of six rule are created these rule are made to make system as human as possible [3]. Diagram of the membership function are also given in Figure 3.

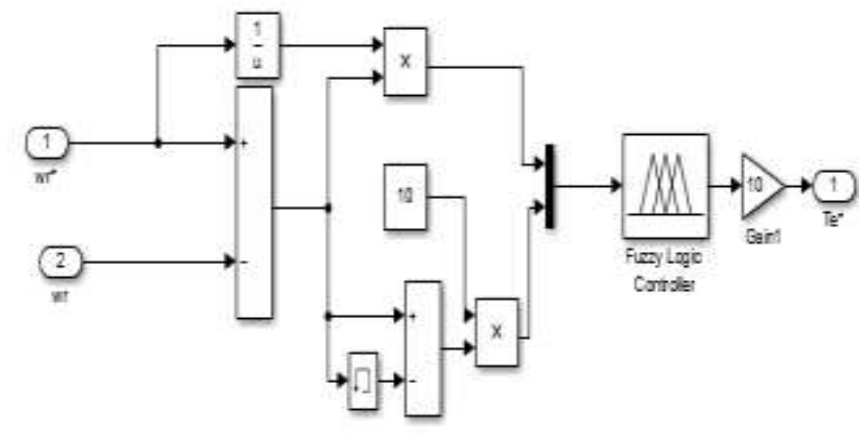

Fig. 2: Sub System of FLC based system

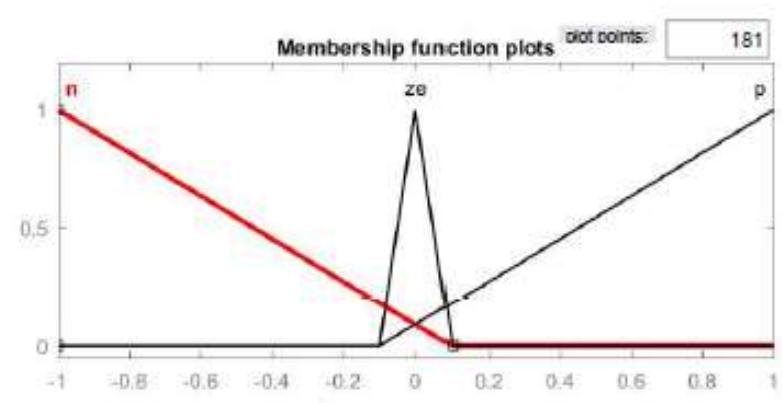

(a)

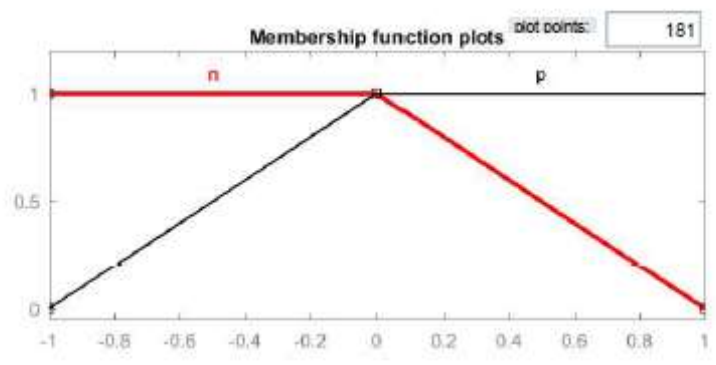

(b)

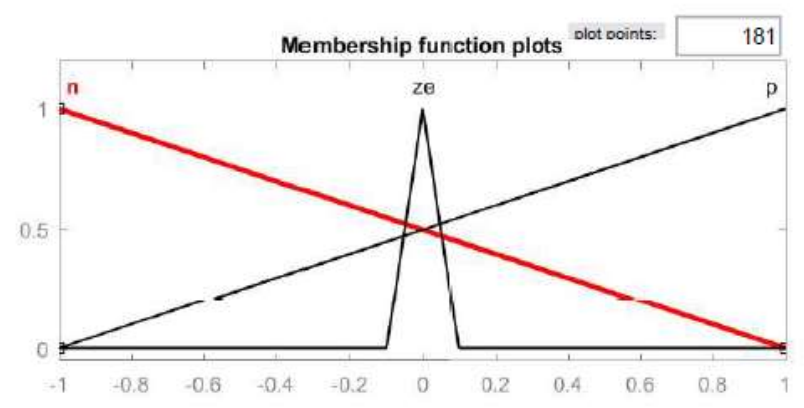

(c)

Fig. 3: Membership function for, (a) speed error, (b) change of speed error, (c) torque reference

So as we can see in figure 3 that Mamdani system is used which work upon the IF-THEN-AND rule.

\section{ANN Technique}

ANN is other technique which is used in this paper. It is based on the biological concept of neural network. It has different interconnected layers which are used to compute the result. Neural network has a interconnected web of network which has neurons in it 
These neurons are designed to process information accurately. Neural network is trained my constantly matching the input and output pattern. In this paper the rest of the block diagram is same as that of the FLC but the only change is ANN subsystem which replace the FLC subsystem as show in fig 4 and 5. Input to the ANN subsystem is same that of the FLC system and output is also the same.

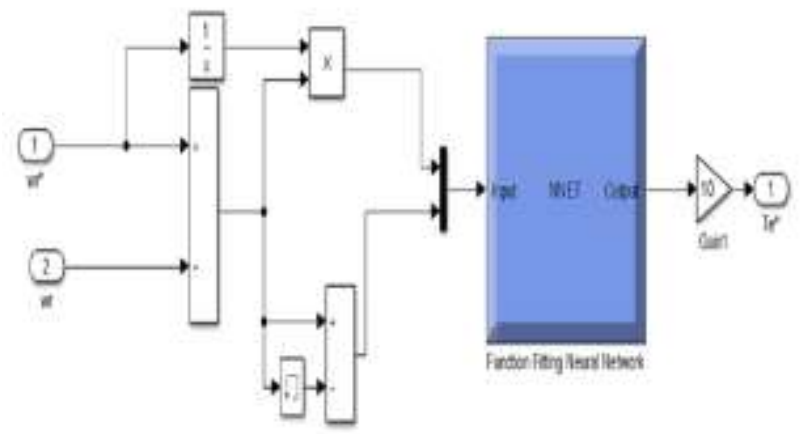

Fig. 4: Subsystem of ANN based system

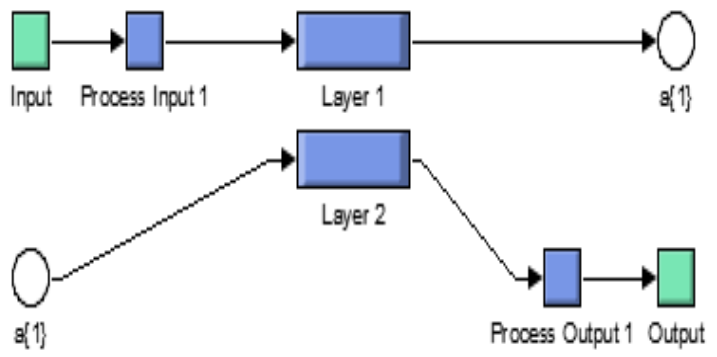

Fig. 5: Layers used in subsystem of ANN based system

So as we can see that in figure 4 and 5 that same delay block is used as was used in FLC based system and total of two layers are used for the proper output with reduced error

\section{SIMULATION RESULTS}

To identify the effectiveness of ANN controller over FLC simulation has been done in MATLAB simulink..

\section{A. Speed Tracking Parameter}

Fig. 6 (a) and (b) demonstrate speed and current responses of a FSTP fed IM drive using a FLC and proposed ANN respectivly.

IM is started under light load toque and speed varies from 0rpm to 100rpm. As we can see the variation of speed in fig 6 we can see that ANN track the reference speed more properly as compared to FLC. Response time of ANN is more fast as compared to FLC as we can see both of these method will not give overshoot. If we consider the current response we can see that FLC will give higher overshoot in current as compared to ANN control and FLC take more time to reach steady state condition as comapared to ANN control.

Other respone related to speed and current are shown in fig 7 .

In which speed is varied from 20rpm to 40rpm and response of current and speed is noted and compared. Here we can see that if IM is runing at a certain speed and there is a sudden change in speed both FLC and ANN work a bit similar as compare to fig 6 . So figure 7 gives good speed tracking performance as compared to figure 6 .

\section{B. Load Torque Disturbance}

Robustness of a system can be identified by changing the load suddenly and that is exacty performed in Fig 8. In this case motor is running at a constant speed of 20rpm and than suddenly at $\mathrm{t}=2 \mathrm{sec}$ a rated torque of $7 \mathrm{~N}$.m is applied. If we compare the speed respone than both FLC and ANN shows a sudden dip of speed but dip in FLC is little bit higher than that of ANN. Current variation in FLC is more as compared to the ANN output as we can see that ANN gives that exact output with minimum variation. Now if we compare the variation in torque variation we will see that variation in torque for FLC case is very significant and for ANN we can see that torque is very much steady about the reference value.
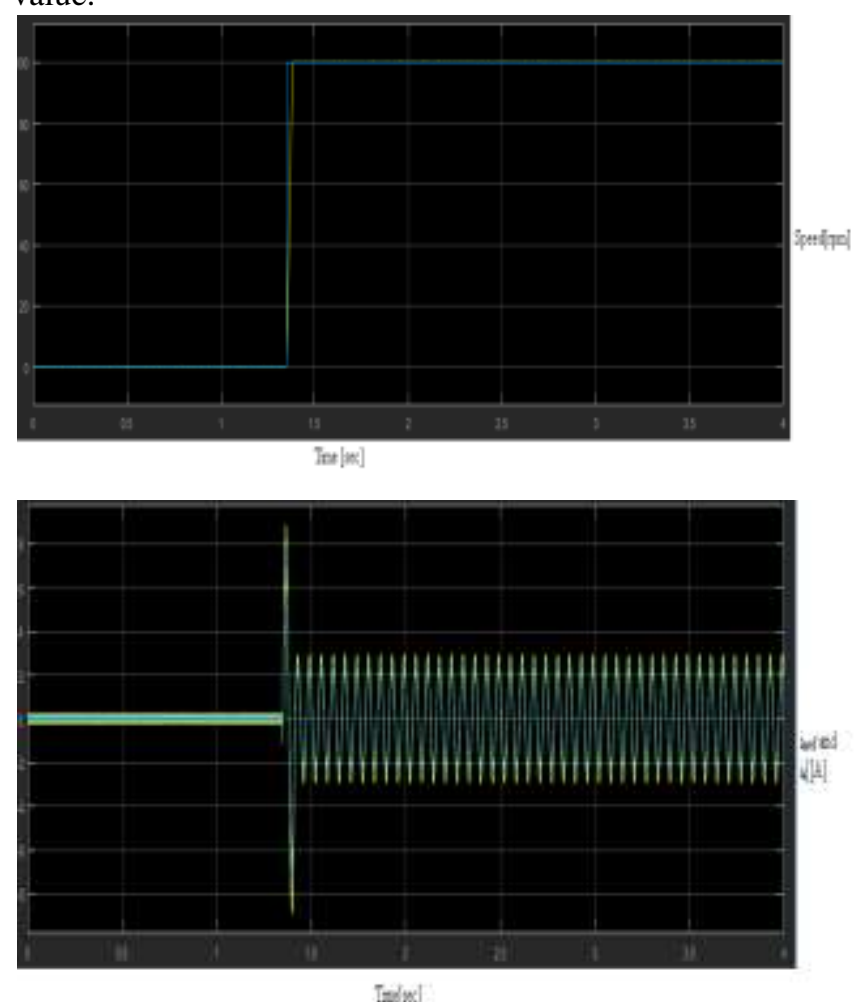

(a)

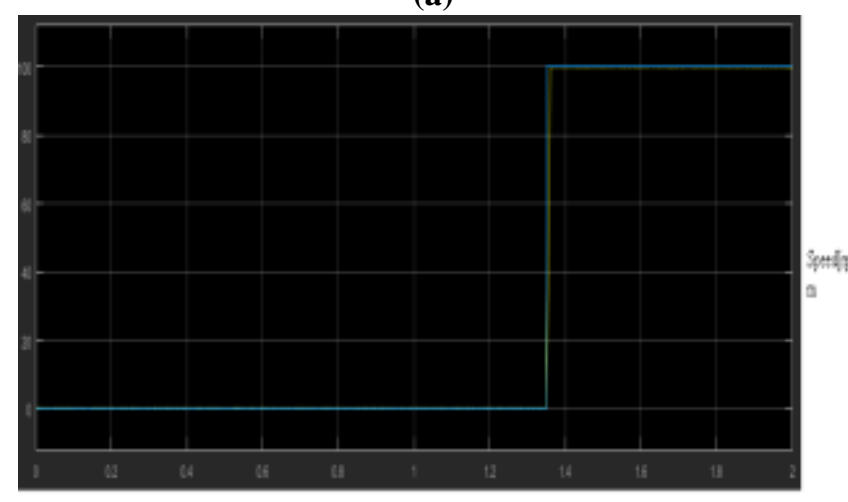

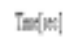

Published By: 
PERFORMANCE RESEARCH OF FOUR SWITCH THREE PHASE INVERTER-FED INDUCTION MOTOR DRIVE AT LOW SPEED USING FUZZY LOGIC AND ARTIFICIAL NEURAL NETWORK

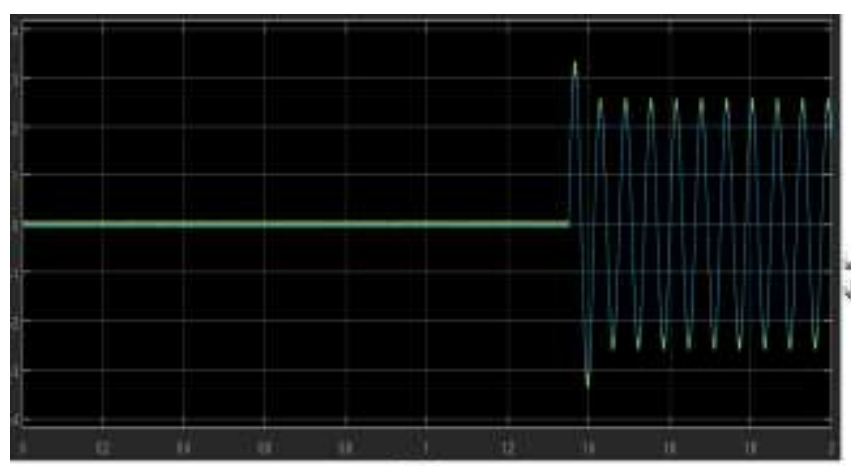

Tertind

(b)

Fig. 6: Result of speed and stator current of FSTP inverter fed IM drive with a step change in speed from Orpm to 100rpm using (a) FLC and (b) ANN controller
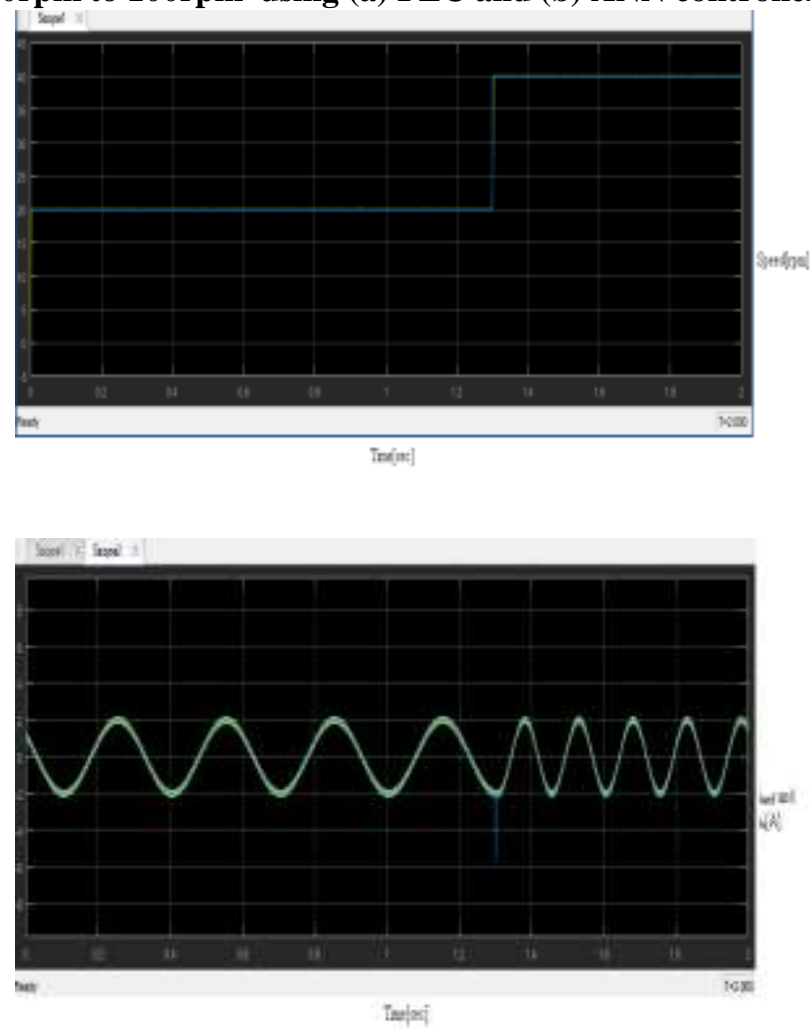

(a)

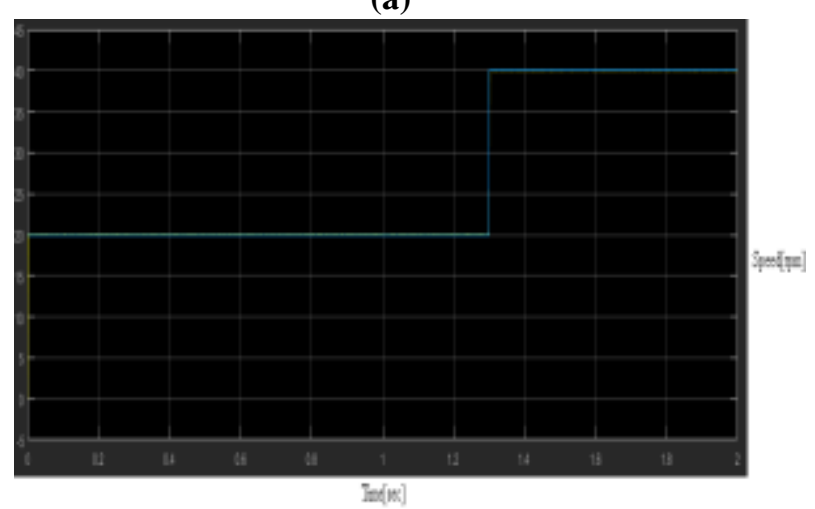

lexisis]
Fig. 7: Result of speed and stator current of FSTP inverter fed IM drive with change in speed from 20 rpm to 40rpm using (a) FLC and (b) ANN controller.
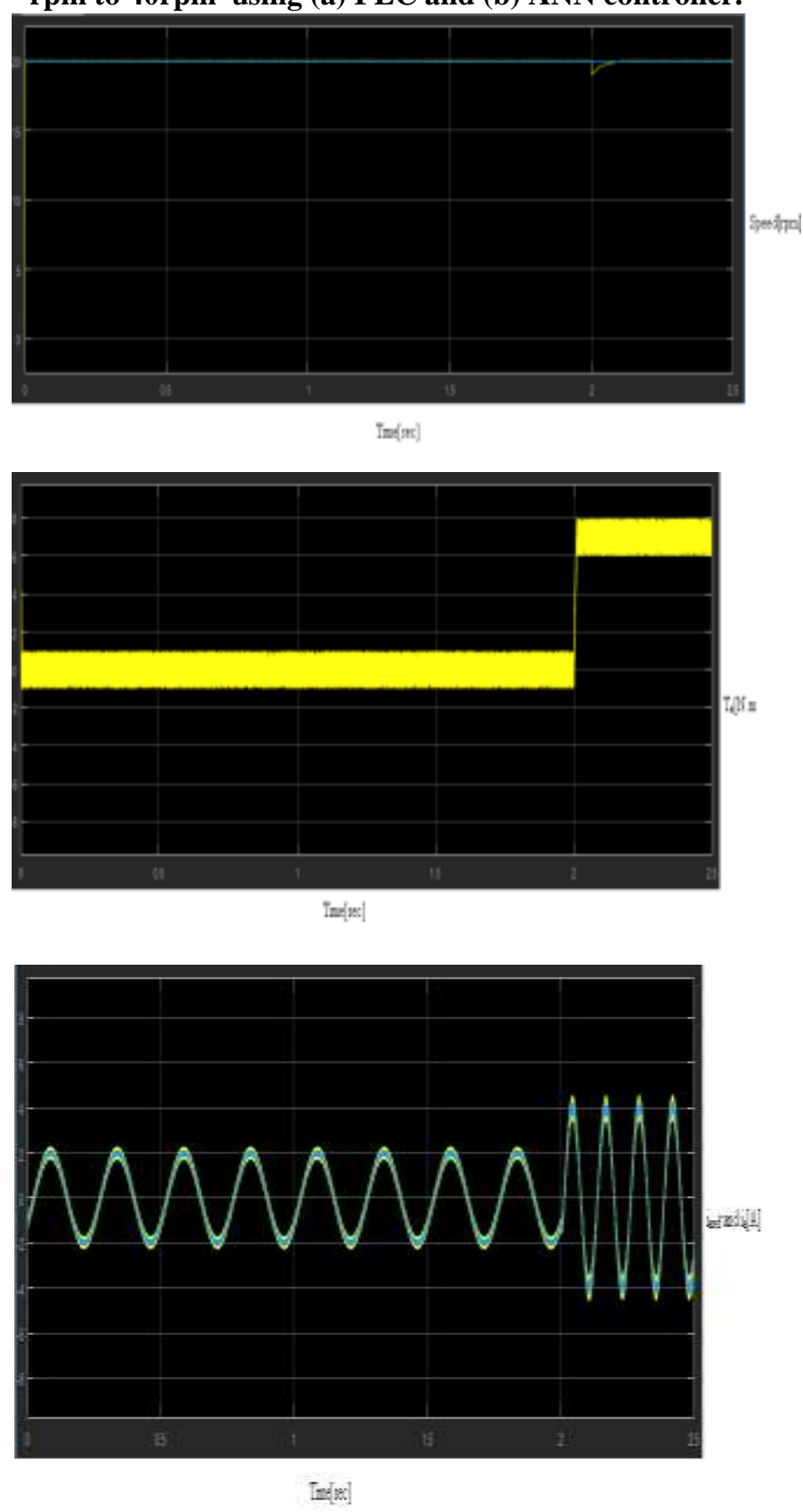

(a) 

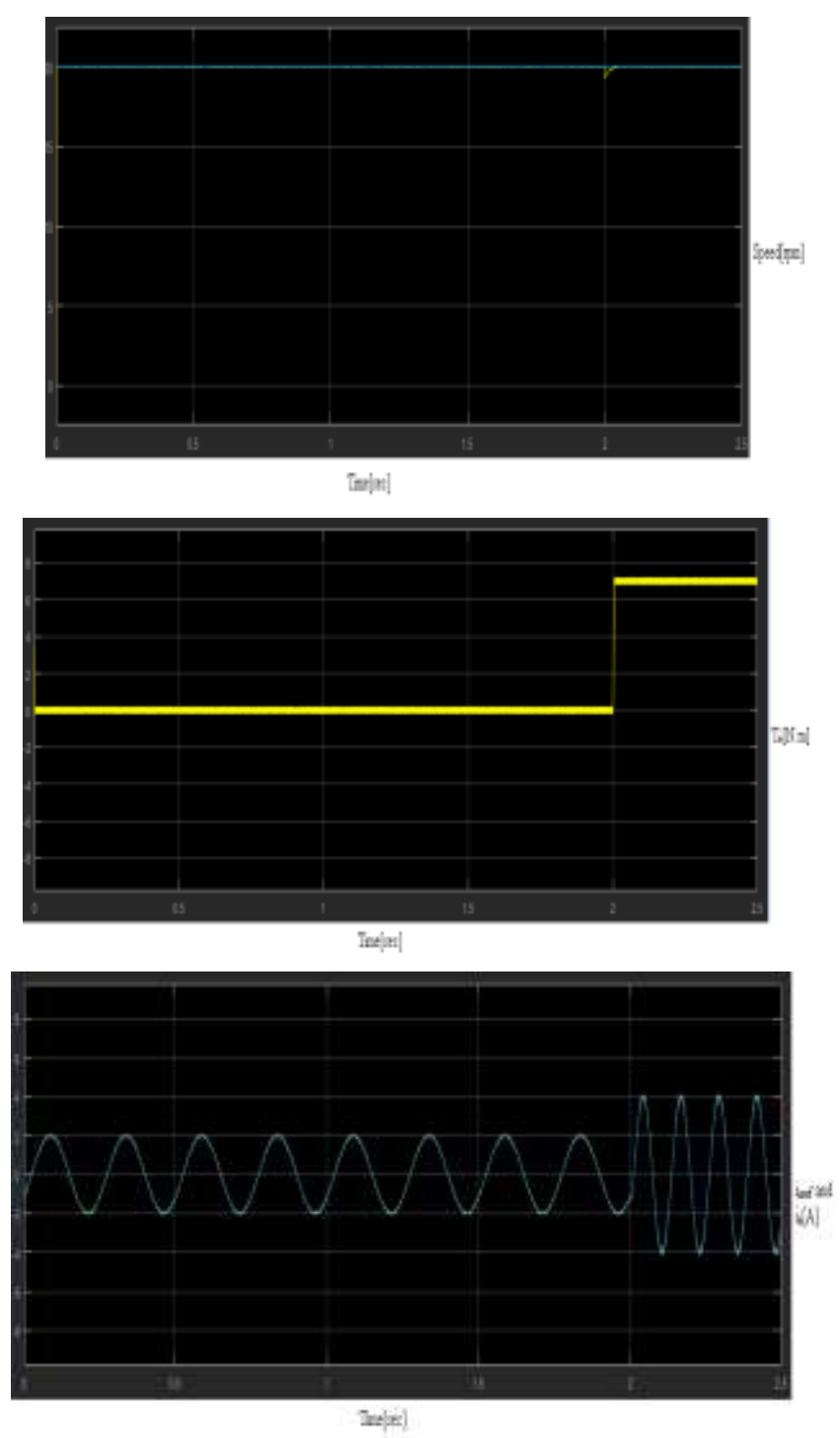

(b)

Fig. 8: Result of Speed and stator current with the sudden change of load torque to $20 \mathrm{~N}$.m at time $2 \mathrm{sec}$ using (a) FLC and (b) ANN controller

\section{V.CONCLUSION}

As we can see in the simulated result that in Figure 6 ANN produces more effective result as compared to its counterpart. ANN gives us lesser ripple in stator current and better speed tracking. Now if we move towards the figure 7 we will get almost equal result for both FLC and ANN in terms of speed as well as stator current. Considering Figure 8 we can see that as we apply the load torque at time two second speed drop in FLC is bit higher than that of ANN and the most significant difference is the torque after two seconds FLC has more ripple in the torque as compared to that of ANN.

\section{REFERENCES}

1. C. B. Jacobina, M. B. d. Correa, T. M. Olivero, A. M. N. Lima and E. R. C. da Silva, "Current control of unbalanced electrical systems," in IEEE Transactions on Industrial Electronics, vol. 48, no. 3, pp. 517-525, June 2001.

2. S. Dasgupta, S. N. Mohan, S. K. Sahoo and S. K. Panda, "Application of Four-Switch-Based Three-Phase Grid-
Connected Inverter to Connect Renewable Energy Source to a Generalized Unbalanced Microgrid System," in IEEE Transactions on Industrial Electronics, vol. 60 no. 3, pp. 1204-1215, March 2013.

3. M. N. Uddin, T. S. Radwan and M. A. Rahman, "Performances of fuzzy-logic-based indirect vector control for induction motor drive," in IEEE Transactions on Industry Applications, vol. 38, no. 5, pp. 1219-1225, Sept.-Oct. 2002.

4. M. Masiala, B. Vafakhah, J. Salmon and A. Knight, "Fuzzy Self-Tuning Speed Control of an Indirect FieldOriented Control Induction Motor Drive," 2007 IEEE Industry Applications Annual Meeting, New Orleans, LA, 2007, pp. 1008-1014.

5. M. N. Uddin and H. Wen, "Development of a Self-Tuned Neuro-Fuzzy Controller for Induction Motor Drives," in IEEE Transactions on Industry Applications, vol. 43, no. 4, pp. 1108-1116, July-aug. 2007.

6. M. Nasir Uddin, Zhi Rui Huang, and A. B. M. Siddique Hossain, "Development and Implementation of a Simplified Self-Tuned Neuro-Fuzzy-Based IM Drive, " IEEE Transactions on Industry Applications, Vol. 50, No. 1, pp. 51-59, January/February 2014

7. M. Hafeez, M. Nasir Uddin, Nasrudin Abd. Rahim, and Hew Wooi Ping, "Self-Tuned NFC and Adaptive Torque Hysteresis-Based DTC Scheme for IM Drive, " IEEE Transactions On Industry Applications, Vol. 50, No. 2, Pp. 1410-1419, March/April 2014.

8. G. R. Arab Markadeh, Ehsan Daryabeigi, Caro Lucas, and M. Azizur Rahman, "Speed and Flux Control of Induction Motors Using Emotional Intelligent Controller," IEEE Transactions on Industry Applications, Vol. 47, No. 3, pp.1126-1135, May/June 2011.

9. AliSaghafinia, Hew Wooi Ping, Mohammad Nasir Uddin, and Khalaf Salloum Gaeid, "Adaptive Fuzzy Sliding-Mode Control Into Chattering-Free IM Drive," IEEE Transactions On Industry Applications, Vol. 51, No. 1, pp. 692-701, January/February 2015.

10. M. Nasir Uddin, Tawfik S. Radwan, and M. Azizur Rahman, "Fuzzy-Logic-Controller-Based Cost-Effective Four-Switch Three-Phase Inverter-Fed IPM Synchronous Motor Drive System," IEEE Transactions on Industry Applications, Vol. 42, No. 1, pp. 21-30, January/February 2006

11. Y. A. Kwon and S. H. Kim, "A new scheme for speedsensorless control of induction motor," IEEE Trans. Ind. Electron., vol. 51, no. 3, pp. 545-550, Jun. 2004.

12. M. S. Zaky and M. K. Metwaly, "A Performance Investigation of a Four-Switch Three-Phase Inverter-Fed IM Drives at Low Speeds Using Fuzzy Logic and PI Controllers," in IEEE Transactions on Power Electronics, vol. 32, no. 5, pp. 3741-3753, May 2017. 